\title{
GEOSUL
}

\section{REPRESENTAÇÕES DOS MORADORES DO ENTORNO DAS ÁREAS DE EXPLORAÇÃO SOBRE A IMPORTÂNCIA E IMPACTOS DA MINERAÇÃO}

\author{
Fredson Pereira da Silva ${ }^{1}$ \\ Geraldo Jorge Barbosa de Moura² \\ Carlos Alberto Batista dos Santos ${ }^{3}$
}

\begin{abstract}
Resumo: A exploração dos recursos do solo tem crescido cada vez mais em diversas partes do mundo, principalmente em relação às explorações minerais. No Brasil, muitas comunidades têm sofrido com os impactos socioambientais decorrentes da exploração desses recursos. Este estudo teve como objetivo investigar as representações dos moradores do entorno de áreas de exploração mineral do gnaisse acerca dos impactos e importância da mineração. Foram investigados o perfil socioeconômico, os impactos positivos e negativos da mineração e a relação comunidade-empresa. Para coleta de dados foram realizadas entrevistas com aplicação de questionários semiestruturados a 87 habitantes, selecionados aleatoriamente, tendo como critério de inclusão a idade $>/=18$ anos e escolaridade, optando-se pelos alfabetizados. Os resultados demostram que, entre os problemas socioambientais, as disfunções do aparelho respiratório, explosão das rochas com consequente modificações na paisagem, perda da fauna e flora, entre outros impactos, vêm gerando conflitos entre a comunidade e a empresa mineradora. É necessário buscar soluções que possam mitigar esses conflitos e reordenar o território ocupado pela comunidade, como também desenvolver ações para recuperação das áreas degradadas.
\end{abstract}

Palavras-chave: Conflitos socioambientais; Territórios tradicionais; Saúde; Paisagem

\section{REPRESENTATIONS OF ENVIRONMENTAL DWELLERS OF THE AREAS OF EXPLORATION ON IMPORTANCE AND IMPACTS OF MINING}

\begin{abstract}
Exploitation of land resources has been increasing in various parts of the world, especially in relation to mineral exploration. In Brazil, many communities have suffered from the socio-environmental impacts resulting from the exploitation of these resources. The objective of this study was to investigate the representations of the residents of the mineral exploration areas of the gneiss about the impacts and importance of mining. The socioeconomic profile, the positive and negative impacts of mining and the communitycompany relationship were investigated. For data collection, interviews were carried out with the application of semi-structured questionnaires to 87 inhabitants, randomly selected, having as inclusion criteria the age $>/=18$ years and schooling, opting for the literate. The results show that among socioenvironmental problems, dysfunction of the respiratory system, explosion of rocks with consequent modifications in the landscape, loss of fauna and flora,

\footnotetext{
${ }^{1}$ Mestrando em Ecologia Humana e Gestão Socioambiental pela Universidade do Estado da Bahia UNEB/Juazeiro. fredson_psilva@ @hotmail.com

${ }^{2}$ Doutor em Ciências Biológicas (UFPB). Professor da Universidade Federal Rural de Pernambuco - UFRPE. Departamento de Biologia - Área de Zoologia. Coordenador do Lab. de Estudos Herpetológicos e Paleoherpetológicos - LEHP. geraldojbm@yahoo.com.br

${ }^{3}$ Doutor em Etnobiologia e Conservação da Natureza (UFRPE), Professor da Universidade do Estado da Bahia, Departamento de Tecnologia e Ciências Sociais. Coordenador do Mestrado em Ecologia Humana e Gestão Socioambiental DTCS/UNEB. cabsantos@uneb.br
} 
among other impacts, has been generating conflicts between the community and the mining company. It is necessary to seek solutions that can mitigate these conflicts and reorder the territory occupied by the community, as well as develop actions to recover degraded areas.

Key-words: Socio-environmental conflicts; Traditional territories; Health; Landscape

\section{REPRESENTACIONES DE LOS MORADORES DEL ENTORNO DE LAS ÁREAS DE EXPLOTACIÓN SOBRE LA IMPORTANCIA E IMPACTOS DE LA MINERÍA}

Resumen: La explotación de los recursos del suelo ha crecido cada vez más en diversas partes del mundo, principalmente en relación a las explotaciones minerales. En Brasil, muchas comunidades han sufrido los impactos socioambientales derivados de la explotación de esos recursos. Este estudio tuvo como objetivo investigar las representaciones de los habitantes del entorno de áreas de explotación mineral del gnaisse acerca de los impactos e importancia de la minería. Se investigó el perfil socioeconómico, los impactos positivos y negativos de la minería y la relación comunidad-empresa. Para la recolección de datos se realizaron entrevistas con aplicación de cuestionarios semiestructurados a 87 habitantes, seleccionados aleatoriamente, teniendo como criterio de inclusión la edad $>/=18$ años y escolaridad, optando por los alfabetizados. Los resultados demuestran que entre los problemas socioambientales, las disfunciones del aparato respiratorio, explosión de las rocas con consecuentes modificaciones en el paisaje, pérdida de la fauna y flora, entre otros impactos, vienen generando conflictos entre la comunidad y la empresa minera. Es necesario buscar soluciones que puedan mitigar esos conflictos y reordenar el territorio ocupado por la comunidad, así como desarrollar acciones para la recuperación de las áreas degradadas.

Palabras clave: Conflictos socioambientales; Territorios tradicionales; Salud; Paisaje

\section{INTRODUÇÃO}

No decorrer da história da humanidade pode-se notar diversas maneiras através das quais os seres humanos se apropriam dos recursos naturais, promovendo a longo prazo o esgotamento desses recursos. A busca por áreas para extração de minérios como o ouro, esmeraldas e gnaisse, produzem impactos ambientais nos territórios tradicionais ocupados por comunidades sertanejas, a exemplo do lançamento das rochas, perda da flora e fauna e contaminação dos recursos hídricos, além de problemas sociais como o abalo na estrutura das residências e o aumento da incidência de doenças respiratórias e auditivas (VASCONCELOS, VASCONCELOS, NETO, 2013; BALZINO et al., 2015; KNABB et al., 2016; FREITAS, MAGRIN, 2013; ZELENÁKOVÁ, ZVIJÁKOVÁ, 2017)

Em diversas partes do mundo, muitas comunidades têm sofrido por conta da mineração, gerando danos aos seres humanos e ao meio ambiente, a exemplo da China, onde mais de 12 mil minas se encontram em atividade. Durante décadas diversos problemas têm 
sido gerados e poucas pesquisas têm sido realizadas no país, com o intuito de minimizar os impactos e os conflitos com as comunidades locais (YAN-XIA et al., 2016).

$\mathrm{Na}$ cidade de Bajo de la Alumbrera, noroeste da Argentina, as comunidades tem sofrido por mais de uma década com a mineração do cobre e do ouro, cerca de dezoito mil pessoas já foram afetadas pelo rompimento do oleoduto das empresas de mineração, o que ocasionou poluição da águas, morte da fauna local e contaminação do solo com enxofre (VACCAREZZA, 2011; GODFRID, 2016).

No Brasil não é diferente, recentemente a barragem da mineradora Samarco S/A na cidade de Mariana - Minas Gerais foi rompida, ceifando vidas humanas, contaminando rios, florestas, aniquilando a fauna e a flora, evento considerado a maior catástrofe ambiental da história do Brasil (LOPES, 2016).

Na região Nordeste do país, a exploração mineral do quartzo na cidade de Pedra Lavrada na Paraíba, trouxe consequências à saúde dos trabalhadores e da comunidade que reside próximo à pedreira, seja por conta dos ruídos ou por conta da poeira, sendo registrado o aumento da incidência de doenças respiratórias, auditivas e visuais, além de afetar a saúde da população de entorno, os abalos sísmicos, causados pela detonação das rochas que provocarama rachadura nas casas e o ultra lançamento de rochas por conta da detonação por explosivos (DANTAS et al., 2015).

A visão da população sobre a exploração de minérios pelas comunidades situadas nas proximidades das áreas de mineração, deve ser investigada, pois a partir das percepções dos residentes poderemos entender até que ponto essas ações tem afetado seu território e sua cultura. Os estudos das percepções são úteis para representar as inter-relações entre o homem e o ambiente, suas expectativas, anseios, satisfações e insatisfações, julgamentos e condutas (FERNANDES et al., 2004; UZN, KELES, 2012).

A percepção é aqui entendida, como fatores internos e socioculturais,que contribuem para a sobrevivência dos seres humanos edo que está ao seu redor. Mesmo assim, nem tudo o que está ao nosso redor pode ser percebido, sendo assim a melhor forma de compreender estes estudos é através da representação da percepção ambiental (SILVA; CHAVES; ALBUQUERQUE, 2016; VILLAR et al., 2008).

A percepção para Ferreira Júnior (2016) é complexa, pois envolve a captura de estímulos e dados ambientais, pelos órgãos dos sentidos, provocando uma representação do meio interno, sendo assim, chega-se a escolhas e decisões para expressar a percepção ambiental. 
O estudo de percepção para Ruoso (2012) é entendido como a inter-relação entre sociedade e natureza e suas alterações do meio natural, percebidas quando estas afetam seu bem estar e seu modo de vida. O mesmo leva em consideração que, a cultura e a realidade afetama percepção, deste modo, entende-se a percepção ambiental como a compreensão do ser humano pelo ambiente e pelos atores que nele vivem.

O uso dos recursos do solo, através da exploração mineral, tem sido objeto de investigação sobre percepção e exploração da mineração, estudo desenvolvido por Liphadzi e Vermaak (2017), investigou as representações dos empregados da empresa de mineração de carvão e ferro na África do Sul e a relação com a contaminação da água pelos rejeitos.Outro estudo sobre extração de ouro na Finlândia, desenvolvido por Lyytimäki e Peltonen (2016), evidencia as críticas da população circunvizinha à implementação da mina, em especial por conta dos riscos potenciais relacionados aos problemas de qualidade da água, poeira e odor.

Mediante o exposto, este trabalho objetiva detectar as representações dos moradores circunvizinhos às áreas de exploração do gnaisse, acerca dos impactos e importância da mineração na cidade de Petrolina, Pernambuco, Nordeste do Brasil.

\section{MATERIAL E MÉTODOS}

\section{Área de estudo}

Este estudo foi realizado na comunidade Vila Renascer, Sítio Serrote Pelado, na zona rural de Petrolina- Pernambuco (Figura 1), localizado a $23 \mathrm{~km}$ da sede do município, a comunidade possui 300 habitantes residentes no entorno de uma mineradora de exploração de gnaisse.

A comunidade de Vila Renascer está posicionada entre inselbergs, morros testemunhos ou isolados, característicos de região semiárida, que são explorados pela atividade econômica dos moradores que residem na área. Os solos da área são do tipo planossolo e neossolo litólico, a vegetação é do tipo caatinga arbustiva densa e esparsa.

Este estudo foi aprovado pelo Comitê de Ética da Universidade do Estado da Bahia, parecer de número: 2.023.539. 

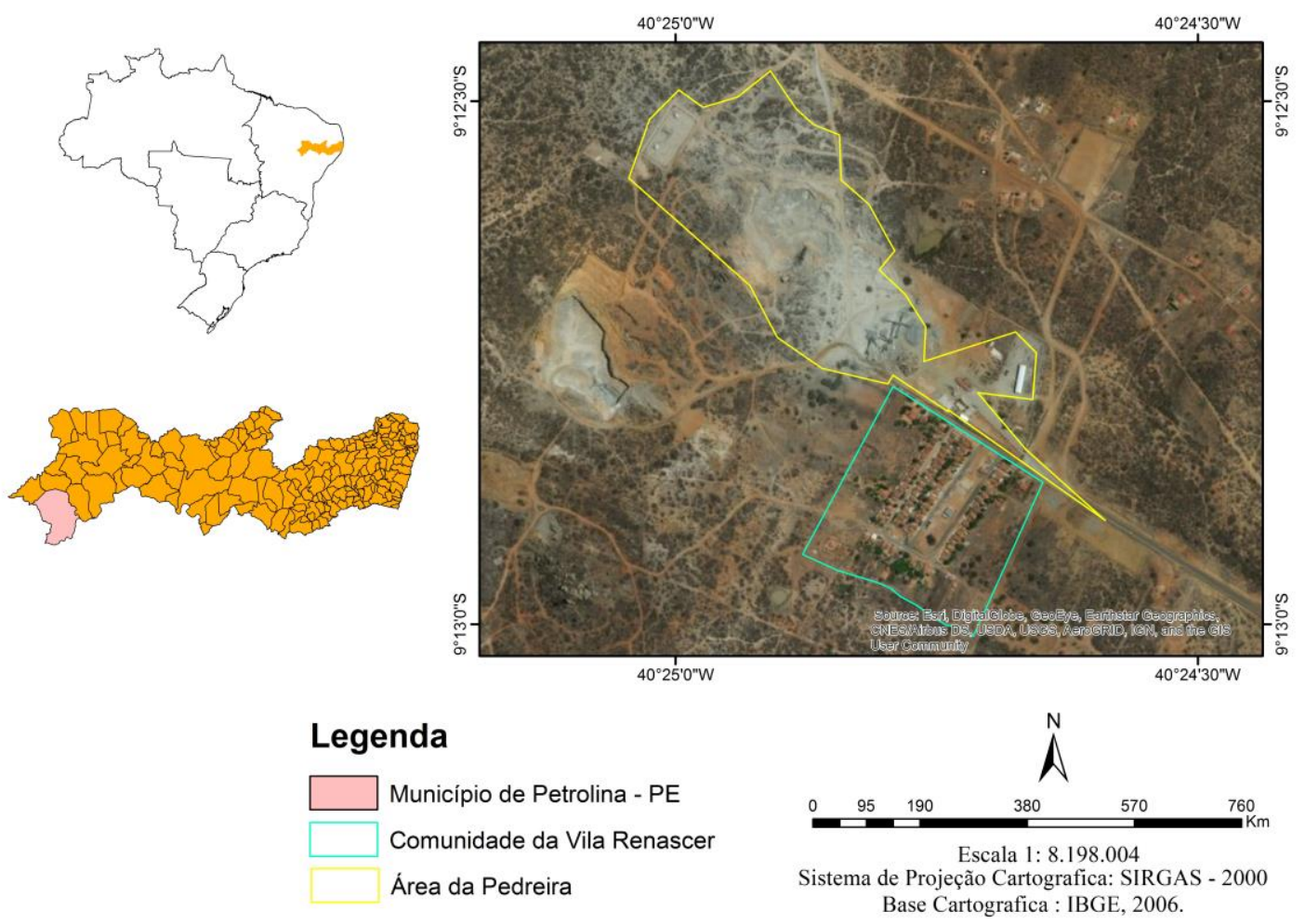

Figura 01: Mapa de localização da comunidade da Vila Renascer em Petrolina, Pernambuco, Nordeste do Brasil.

Elaboração: Fredson Pereira da Silva (2017)

\section{COLETA DE DADOS}

Os dados foram coletados a partir de entrevistas realizadas no primeiro semestre de 2017, com a população residente no entorno de uma mineradora de gnaisse, acerca dos impactos e importância da mineração. As entrevistas forma conduzidas, com a aplicação de questionários semiestruturados (GIL, 2002; ALBUQUERQUE et al., 2014; SANTOS; NÓBREGA ALVES, 2016; SANTOS et al., 2016). Os questionários abordavam questões sobre a faixa etária, sexo, naturalidade, ocupação, renda, condição de moradia, e influência da mineradora no cotidiano da população.

A amostragem foi aleatória, sendo selecionados 87 informantes, o que corresponde a 29\% da população total (300 habitantes). Como critério para inclusão dos participantes na pesquisa foi adotado a idade $>/=18$ anos e escolaridade, optando-se pelos alfabetizados. Os resultados das entrevistas foram organizados em planilha, analisados e calculados o percentual relativo dos resultados. 


\section{RESULTADOS DISCUSSÃO}

\section{Perfil socioeconômico da população}

Os dados socioeconômicos dos 87 informantes estão listados na Tabela 01. A maioria dos participantes da pesquisa são mulheres (52,8\%) com idade entre 18 a 29 anos (36,7\%).

Em relação às condições de moradia dos entrevistadosa maioria reside em casa própria (75,6\%). A renda familiar predominante é de 1 salário mínimo $(66,6 \%)$ por família, sendo estas compostas por 3 ou 4 pessoas $(31,6 \%)$. Em relação à escolaridade 60,2\% possui ensino fundamental incompleto

Quanto a ocupação profissional, 56\% atuam em atividades ligadas direta ou indiretamente à mineradora, em especial nas atividade de corte de rochas. Quase todos os entrevistados são naturais da mesorregião do vale do São Francisco,ou das cidades vizinhas de Araripina, Lagoa Grande, Serra Talhada, Sertânia, Belo Jardim, Arco Verde no estado de Pernambucoe do município baiano de Juazeiro - Bahia. Em relação ao tempo de moradia, o destaque são para aqueles que residem na comunidade entre 10 e 30 anos (52\%).

Para Matos (2012), no Brasil no século XXI, diversas migrações aconteceram em busca de emprego devido ao processo de industrialização, o mesmo destaca a exploração de minérios como consequência da migração, possivelmente foi isto que aconteceu na comunidade da Vila Renascer, sendo fundada em decorrência do estabelecimento da mineração dognaisse (VIEIRA, 2011). 
Tabela 01: Dados socioeconômicos dos informantes da comunidade da Vila Renascer em Petrolina, Pernambuco nordeste do Brasil $(n=87)$.

\begin{tabular}{|c|c|}
\hline Sexo & $\mathbf{N}^{0}$ de entrevistados \\
\hline Homens & $41(47,1 \%)$ \\
\hline Mulheres & $46(52,8 \%)$ \\
\hline \multicolumn{2}{|l|}{ Idade } \\
\hline 18 a29 anos & $32(36,7 \%)$ \\
\hline 29 a 38 anos & $16(18,3 \%)$ \\
\hline 39 a 48 anos & $17(19,5 \%)$ \\
\hline 49 a 58 anos & $15(17,2 \%)$ \\
\hline $58 \mathrm{ou}+$ anos & $7(8 \%)$ \\
\hline \multicolumn{2}{|c|}{ Condições de Moradia } \\
\hline Alugada & $17(20 \%)$ \\
\hline Própria & $62(75,6 \%)$ \\
\hline Apropriada & - \\
\hline Cedida & $3(3,6 \%)$ \\
\hline \multicolumn{2}{|l|}{ Renda Mensal } \\
\hline Não possui renda fixa & \\
\hline 1 salário mínimo & $58(66,6 \%)$ \\
\hline 2 salário mínimo & $28(32,1 \%)$ \\
\hline 3 salário mínimo & $1(1,1 \%)$ \\
\hline \multirow[t]{2}{*}{4 salário mínimo } & - \\
\hline & - \\
\hline \multicolumn{2}{|l|}{5 salário mínimo } \\
\hline \multicolumn{2}{|l|}{ Escolaridade } \\
\hline Ensino F. Incompleto & $47(60,2 \%)$ \\
\hline Ensino F. Completo & $12(15,3 \%)$ \\
\hline Ensino Médio Incompleto & $9(11,5 \%)$ \\
\hline Ensino Médio Completo & $5(6,4 \%)$ \\
\hline Ensino Superior Incompleto & $3(3,8 \%)$ \\
\hline Ensino Superior Completo & $2(2,5 \%)$ \\
\hline \multicolumn{2}{|l|}{ Profissão } \\
\hline Aposentado & $9(11,1 \%)$ \\
\hline Dona de casa & $1(1,2 \%)$ \\
\hline Eletricista & $1(1,2 \%)$ \\
\hline Agricultor & $1(1,2 \%)$ \\
\hline Autônomo & $23(28,3 \%)$ \\
\hline Trabalha na mineradora & $20(24,6 \%)$ \\
\hline Cortador de rocha & $26(32 \%)$ \\
\hline \multicolumn{2}{|l|}{ Naturalidade } \\
\hline Nasceu na comunidade & $63(77,7 \%)$ \\
\hline Piauí & $2(2,4 \%)$ \\
\hline Bahia & $7(8,6 \%)$ \\
\hline São Paulo & $3(3,7 \%)$ \\
\hline Ceará & $4(4,9 \%)$ \\
\hline Paraíba & $2(2,4 \%)$ \\
\hline \multicolumn{2}{|c|}{ Tempode moradia } \\
\hline Até 10 anos & $19(22,6 \%)$ \\
\hline 10 a 21 anos & $26(30,9 \%)$ \\
\hline & $19(22,6 \%)$ \\
\hline
\end{tabular}




\begin{tabular}{l|c}
\hline 31 a 40 anos & $13(15,4 \%)$ \\
40 ou + anos & $7(8,3 \%)$ \\
\hline \multicolumn{1}{c|}{$\mathbf{N}^{\mathbf{0}}$ de pessoas na família } & $18(22,7 \%)$ \\
\hline 1 a 2 pessoas & $29(36,7 \%)$ \\
3 a 4 pessoas & $25(31,6 \%)$ \\
5 a 6 pessoas & $7(8,8 \%)$ \\
7 a 8 pessoas & \\
\hline
\end{tabular}

Percepção da população circunvizinha referente aos impactos ambientais decorrentes da atividade de mineração do gnaisse na Vila Renascer, cidade de Petrolina, estado de Pernambuco, Nordeste do Brasil.

O principal impacto identificado pelos entrevistados foi a poeira (Figura 02), responsável pelos problemas respiratórios que afetam grande parte da população $(20,4 \%)$.

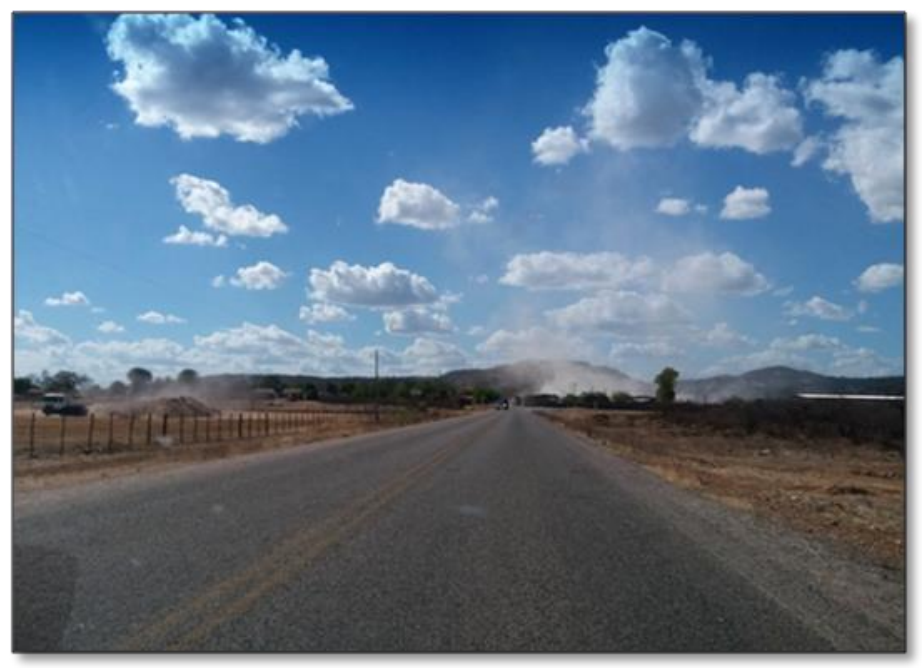

Figura 02: Emissão de poeira pela britagem da rocha na área adjacente da comunidade da Vila Renascer em Petrolina, Pernambuco Nordeste do Brasil.

Fonte: Acervo dos Autores (2017)

Para Bisquert, Castejon e Fernandez (2017), a emissão de poeira por empresas de mineração tem efeitos adversos sobre as populações que residem nas áreas adjacentes, comprometendo a saúde e depositando poeira na atmosfera. A dependerdo tipo de rocha pode comprometer a qualidade do ar além dos parâmetros físico-químicos do solo. 
De acordo com Cabral, Pereira e Alves (2012), problemas respiratórios podem ocorrer quando a população fica exposta à inalação de materiais particulados, eliminados pela mineração. Como exemplo temos a silicose, doença causada pela inalação de pequenas partículas de sílica cristalina, encontrada no gnaisse, provocando inflamação e cicatrização em forma de lesões do pulmão. Os mesmos autores registraram a ocorrência de silicose numa pedreira no município de Campina Grande, Paraíba, demonstrando que a silicose provoca dificuldades respiratórias e baixa oxigenação no sangue, além de tonturas, fraquezas e náuseas, chegando a incapacitar o trabalhador da mineração e promovendo a incidência da doença na população de entorno.

Questionados sobre a poluição sonora (Tabela 02),os informantes responsabilizam a empresa de mineração, por sua proximidade da vila e em relação às consequências da poluição sonora, a perturbação do sono $(n=21)$ é o maior problema citado. A poluição sonora é resultante da detonação da rocha na mineradora, deixando os moradores assustados e preocupados com suas residências, segundo Bacci, Landim e Eston (2006), detonações da rocha expressam susto e atrapalham as atividades diárias. Sobre este fato, alguns informantes evitam se pronunciar pois trabalham na empresa.

Em relação à influência da mineração na comunidade, destaca-sea geração de emprego e a venda da rocha, vitais para complementar a renda das famílias. Negativamente apontam o barulho da britação da rocha, a poeira e o abalo físico das residências e edificações públicas como as igrejas (Figura 03).

"Toda vez que explode a pedra a casa fica rachada e tem que consertar direto", "a vizinha teve uma janela quebrada por causa da explosão" (Informante A) 


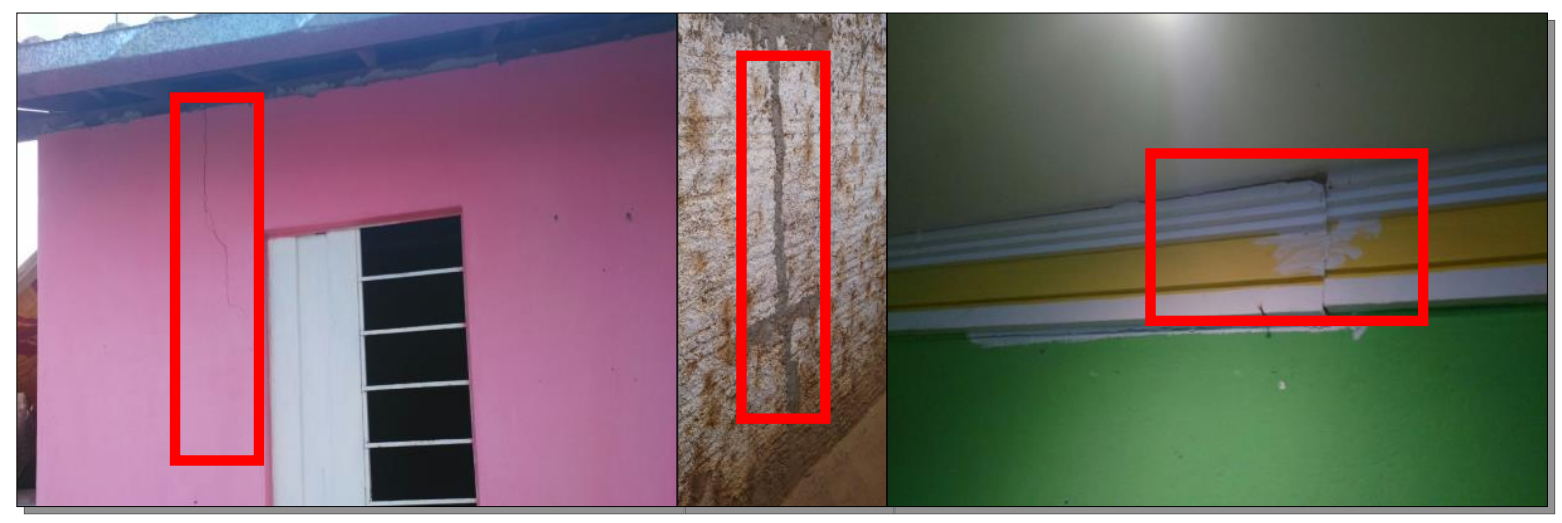

Figura 03: Casas rachadas por conta da detonação da rocha na comunidade da Vila Renascer em Petrolina, Permanbuco Nordeste do Brasil.

Fonte: Acervo dos autores (2017)

Lima e Teixeira (2006); Naves, Fernandes (2015) apontam que as atividades das mineradoras trazem para as comunidades o desenvolvimento local, contribuindo na renda e na melhoria da qualidade de vida da população, contudo, apesar do desenvolvimento,acarreta também problemas socioambientais como a exposição ao barulho, casa rachadas e vibração do terreno.

Pontes,Farias e Lima (2013), comprovaram que o desmonte de rochas com explosivos causam abalos sísmicos, emissão de gases e poeira, provocando a poluição do ar e ultra lançamento de sedimentos rochosos, como também a perda da flora e da fauna, além da degradação da paisagem.

\section{FAUNA E FLORA}

O levantamento do sistema biogeográfico da comunidade da Vila Renascer pode ser visto na tabela (Tabela 02 ). 


\section{TABELA 02: DADOS DA FAUNA E FLORA DA COMUNIDADE DA VILA RENASCER EM PETROLINA, NORDESTE DO BRASIL.}

\begin{tabular}{|c|c|}
\hline \multicolumn{2}{|c|}{ Espécies da fauna encontradas ao redor da comunidade após a mineradora } \\
\hline & Total de entrevistados \\
\hline Domésticos (cavalo, cachorro, burro, galinha) & $48(53,3 \%)$ \\
\hline Tatu & $14(15,5 \%)$ \\
\hline Gambá & $6(6,6 \%)$ \\
\hline Raposa & $2(2,2 \%)$ \\
\hline Tamanduá mirim & $1(1,1 \%)$ \\
\hline Sagui & $3(3,3 \%)$ \\
\hline Escorpião & $4(4,4 \%)$ \\
\hline Aves & $3(3,3 \%)$ \\
\hline Préa & $1(1,1 \%)$ \\
\hline Cobra & $7(7,7 \%)$ \\
\hline Rato & $1(1,1 \%)$ \\
\hline \multicolumn{2}{|c|}{ Espécies da fauna que eram encontradas ao redor da comunidade antes da mineradora } \\
\hline Domésticos (cavalo, cachorro, burro, galinha) & $22(33,8 \%)$ \\
\hline Tatu & $15(23 \%)$ \\
\hline Preá & $4(6,15 \%)$ \\
\hline Raposa & $1(1,5 \%)$ \\
\hline Gambá & $2(3 \%)$ \\
\hline Cutia & $2(3 \%)$ \\
\hline Tamanduá & $1(1,5 \%)$ \\
\hline Calamgo & $1,5 \%)$ \\
\hline Cobra & $10(15,3 \%)$ \\
\hline Mocó & $1(1,5 \%)$ \\
\hline Ave & $2(3 \%)$ \\
\hline Caititu & $2(3 \%)$ \\
\hline \multicolumn{2}{|c|}{ Causas da redução das espécies da fauna } \\
\hline Explosões da rocha & $1(1,5 \%)$ \\
\hline Seca e caça & $1(1,5 \%)$ \\
\hline Não respondeu & $85(97 \%)$ \\
\hline \multicolumn{2}{|c|}{ Espécies da fauna raras } \\
\hline Preá & $1(2,3 \%)$ \\
\hline Tatu & $4(9,3 \%)$ \\
\hline Cascavel & $1(2,3 \%)$ \\
\hline \multicolumn{2}{|c|}{ Espécies da flora encontradas ao redor da comunidade } \\
\hline Barauna & $6(6,6 \%)$ \\
\hline Aroeira & $5(5,5 \%)$ \\
\hline Angico & $8(8,8 \%)$ \\
\hline Umburuçu & $1(1,1 \%)$ \\
\hline Jurema & $12(13,3 \%)$ \\
\hline Macambira de flecha & $1(1,1 \%)$ \\
\hline Xique-xique & $2(2,2 \%)$ \\
\hline Mandacaru & $5(5,5 \%)$ \\
\hline Faveleira & $2(2,2 \%)$ \\
\hline Juazeiro & $2(2,2 \%)$ \\
\hline Umbuzeiro & $13(14,4 \%)$ \\
\hline Jatobá & $1(1,1 \%)$ \\
\hline Quebra-faca & $1(1,1 \%)$ \\
\hline Catingueira & $13(14,4 \%)$ \\
\hline Neem & $7(7,7 \%)$ \\
\hline
\end{tabular}




\begin{tabular}{|c|c|}
\hline Umburana & $10(11,1 \%)$ \\
\hline Plantas rasteiras & $1(1,1 \%)$ \\
\hline \multicolumn{2}{|c|}{ Espécies da flora que eram encontradas ao redor da comunidade } \\
\hline Barauna & $6(9,6 \%)$ \\
\hline Umburuçu & $2(3,2 \%)$ \\
\hline Umburana & $4(6,6 \%)$ \\
\hline Xique-xique & $3(4,8 \%)$ \\
\hline Aroeira & $5(8 \%)$ \\
\hline Coroa de frade & $2(3,2 \%)$ \\
\hline Mandacaru & $3(4,8 \%)$ \\
\hline Angico & $5(11,3 \%)$ \\
\hline Quebra-faca & $2(3,2 \%)$ \\
\hline Faveleira & $1(1,6 \%)$ \\
\hline Catingueira & $10(16,1 \%)$ \\
\hline Juazeiro & $1(1,6 \%)$ \\
\hline Jatobá & $3(4,8 \%)$ \\
\hline Macanbira de flecha & $1(1,6)$ \\
\hline Jurema & $6(9,6 \%)$ \\
\hline Umbuzeiro & $5(8 \%)$ \\
\hline \multicolumn{2}{|c|}{ Causas da redução das espécies da flora } \\
\hline Desmatamento; exploração de areia; exploração para madeira & $4(9,3 \%)$ \\
\hline Chuva & $1(2,3 \%)$ \\
\hline Não ocorreu & $2(4,6 \%)$ \\
\hline \multicolumn{2}{|c|}{ Espécies da flora raras } \\
\hline Jurema & $8(18,6 \%)$ \\
\hline Caatingueira & $5(11,6 \%)$ \\
\hline Jatobá & $3(6,9 \%)$ \\
\hline Umbuzeiro & $5(11,6 \%)$ \\
\hline Mandacaru & $2(4,6 \%)$ \\
\hline Barauna & $5(11,6 \%)$ \\
\hline
\end{tabular}

A fauna conhecida pelos informantes está mais restrita aos animais domésticos o que é demonstrado pelo número de citações antes $(53,3 \%)$ e depois $(33,8 \%)$ da instalação da mineradora (Tabela 03).

Possivelmente o desaparecimento de espécies da fauna silvestre se deve às atividades de mineração, como exemplo temos o mocó (Kerodon rupestris), que se refugia entre as rochas e faz sua morada, e do caititu (Pecari tajacu), por conta da perda da biodiversidade vegetal.

“Muitos anos a trás nós via um macaco meio amarelo lá em cima da serra e depois que começou quebra a pedra ele sumiu"(Informante B).

A exploração da rocha, é a outra causa apontada pelos moradores da redução de espécies,o que é corroborado pelos estudos de Pontes, Farias e Lima (2013) e Andrade e 
Azevedo (2015); ALVES, ARAÚJO, NASCIMENTO (2008), para estes estudiosos, a detonação das rochas nos inselbergs, em áreas de caatinga, promovem a redução da biodiversidade faunística por conta do barulho e das explosões condicionando a migração de aves e mamíferos.Outros associam o desaparecimento de espécies como preá (Galea spixii), do tatu peba (Euphractus sexcinctus) e da cascavel (Crotalus durissus terrificus), à seca e à caça desses animais. A caça de subsistência é uma atividade antiga e representa uma forma tradicional de manejo da fauna, tendo um papel socioeconômico de fornecer carne às famílias locais (ALVES; GONÇALVES; VIEIRA, 2012). No período de seca alguns habitats podem ser alterados, com falta de água ou alimento assim, essas espécies podem buscar novas áreas para garantir sua sobrevivência (OLIVEIRA; GONÇALVES;BONVICINO, 2003).

Em relação às espécies vegetais nas áreas adjacentes da comunidade, as mais citadas foram à catingueira (Caesalpinia pyramidalis) e o umbuzeiro (Spondias tuberosa) ambas com 13 citações, seguidas da jurema (Mimosa tenuiflora) com 12 citações.

Observa-se que antes da implantação da mineradora existia uma vegetação de caatinga densa, com maior abundância de espécies, o desmatamento para retirada da rocha, queimadas e abertura de novas vias de acesso (Figura 04 A e B), são apontadas como as principais causas do desaparecimento das espécies da flora local sendo mais afetadas a jurema, catingueira, umbuzeiro e baraúna. A exploração de minérios próximo às áreas de vegetação acarreta a retirada da mesma para deposição dos materiais explorados, promovendoa degradação visual da paisagem (PONTES; FARIAS; LIMA, 2013; FALEIRO; LOPES, 2010).
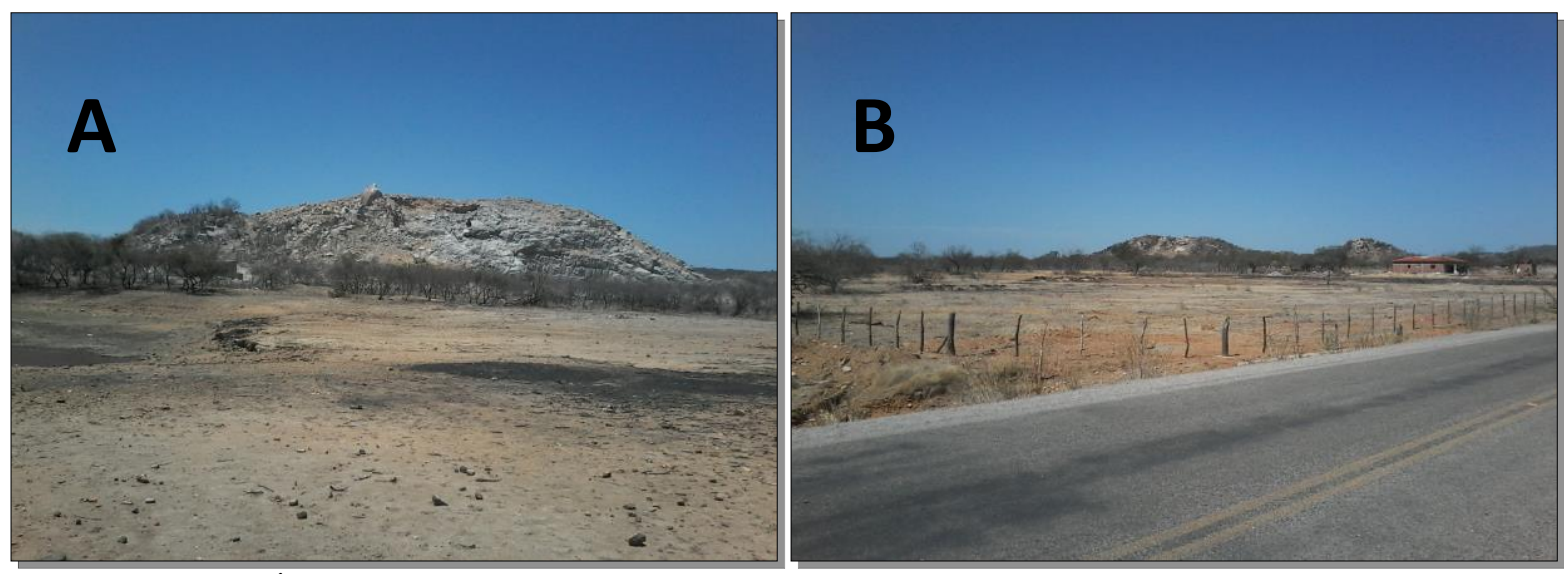

Figura 04A: Área com vegetação retirada para exploração do gnaisse; 04B: Solo exposto e sem espécies nativas da caatinga.

Fonte: Acervo dos Autores (2017) 


\section{RELAÇÃO DA POPULAÇÃO LOCAL COM A EMPRESA}

A maioria dos informantes $(48,2 \%)$ concordam que a empresa de mineração contribui com a melhoria da qualidade dos moradores da Vila Renascer, principalmente na geração de emprego e renda $(5,7 \%)$, mas indicam que a perda da biodiversidade aumentou muito desde a instalação da mesma. Estudo desenvolvido na comunidade de Kivalina, Alasca, EUA, os moradores expressam sua preocupação com a degradação do ambiente e saúde humana da população em torno da mineradora e acreditam que as práticas ali realizadas têm afetado suas colheitas, vegetação e fauna (PRNO, 2013), assim percebemosque as mudanças na comunidade são satisfatórias sob a perspectiva econômica mas não ambiental.

Entre os problemas de saúde são citadas as doenças respiratórias como falta de ar, pneumonia, silicose,dores de cabeça e dor no ouvido, além destas, foram citadas doenças ocupacionais como os problemas de coluna e acidentes de trabalho, cortes e perda de dedos da mão. Acidentes de trabalho se tornaram um problema de saúde global por causa do não uso dos equipamentos de proteção individual, os EPI (XIAO et al., 2017).

Para Jácome e Pereira (2016), Mcelin e Bellini (2008) quando não existe um acompanhamento técnico, conscientização e manuseio adequado dos materiais para exploração da rocha problemas de saúde podem ocorrer como os citados pelos moradores da Vila Renascer.

Em relação às atividades de recuperação do solo e da vegetação da caatinga, o plantio de mudas nas áreas exploradas é realizado com espécies exóticas como oNeem, utilizado na arborização urbana, como quebra-vento e sombra para as residências (Figura 05).

Reclamações à justiça por problemas gerados pela empresa são comuns, principalmente em relação às casas rachadas em decorrência das explosões, no entanto, os moradores temem que com as reclamações a empresa feche as portas.

"Se houverreclamações a empresa pode fechar, e a gente não terá mais dinheiro para se alimentar" (Informante C).

Alguns dos informantes relatam que não ocorre denúncias (40,6\%), no entanto, estes tem alguma ligação com a empresa e ficam receosos em se expor e perder seus empregos. Conflitos socioambientais entre comunidades e mineradoras no semiárido nordestino são comuns, (PATRÍCIO; SILVA; RIBEIRO, 2013; PONTES; LIMA; SILVA, 2016; RUFINO, 
FARIAS, SANTAS NETO, 2007), necessitando de estudos para reordenaçãodos territórios nas comunidades atingidas, como também a necessidade de práticas mitigadoras para redução dos impactos, como orientação da frente de lavra, controle da detonação e implantação de corredores ecológicos (DANTAS et al., 2015).

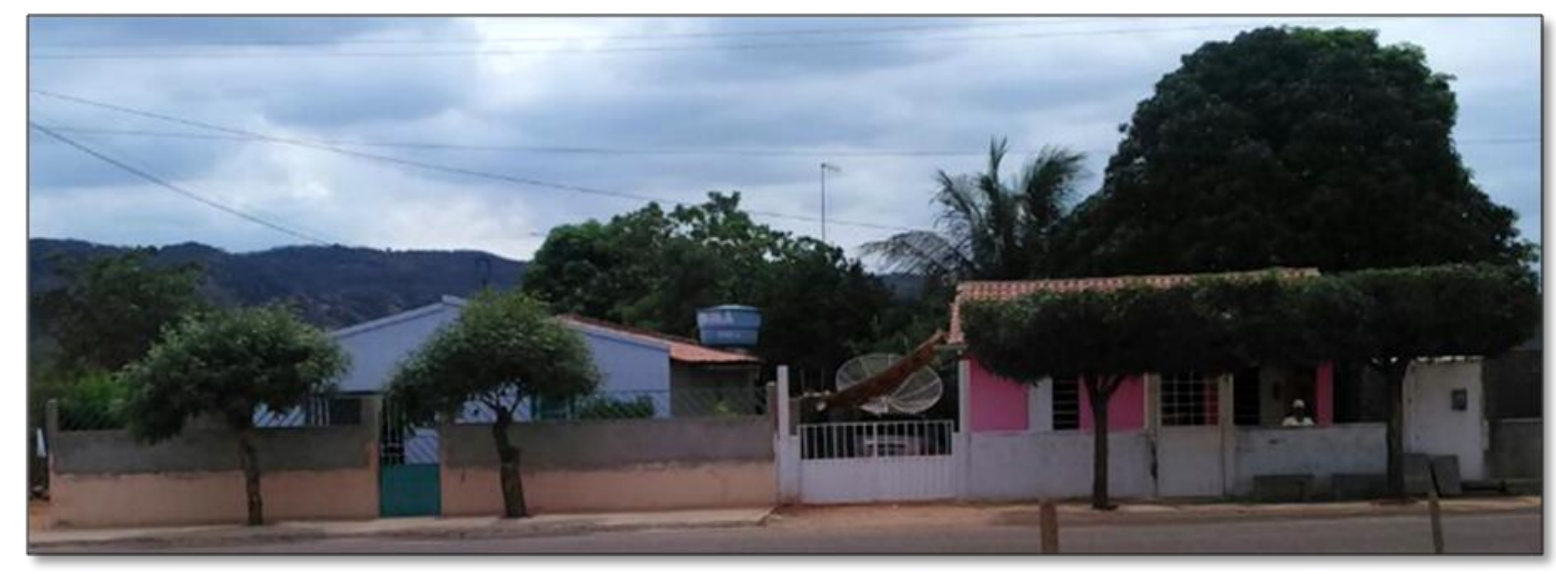

Figura 05: Plantação de Neem na Comunidade da Vila Renascer em Petrolina, Pernambuco Nordeste do Brasil.

Fonte: Acervo dos Autores (2017)

\section{CONSIDERAÇÕES FINAIS}

Diante dos dados apresentados, nota-se que a comunidade da Vila Renascer está em constante transformação do seu território, economia, paisagem e meio ambiente. A mineração do gnaisse no território tradicional promove vários impactos socioambientais para a população, tanto na questão da geração de renda, como na migração de pessoas de outros estados para a comunidade.

Em relação aos impactos ambientais, gerados, a poeira, vibração do terreno, ultra lançamento das rochas, problemas respiratórios, acidentes de trabalho, irritaçãonos olhos, redução da biodiversidade faunística e florística são as principais consequências da exploração mineral.

Para a população residente, os impactos socioambientais, são perceptíveis nas áreas adjacentes da comunidade, mesmo assim, diversos moradores têm receio de denunciar ao poder público as ações impactantes causadas pela mineradora, apesar de todos impactos causados no meio ambiente e na sua qualidade de vida, por ser a única fonte de renda de muitos moradores. 
Ações de recuperação das áreas degradadas como enclausuramento da fonte poluidora, aspersão de água, isolamento da fonte de ruído, recatingamento das espécies arbóreas, e ações que visem mitigar os conflitos socioambientais, promovendo uma mineração sustentável, com vistas à reordenação do território, devem ser prioridade da empresa, para isso é necessário compreender que uma mineração sustentável, busca minimizar os impactos ambientais e manter certos níveis de proteção ecológica e de padrões de qualidade ambientais (ENRÍQUEZ; FERNANDES; ALAMINO, 2011), além de garantir o bem-estar socioeconômico da população.

Além das ações de recuperação propostas e efetivadas pelas mineradoras, é necessário implementar a fiscalização pelos poderes públicos e agências ambientais constituídas para este fim. A legislação trabalhista brasileira, obriga as empresas a avaliar e mitigar os impactos ambientais e amplia o quadro regulatório sobre uso sustentável dos recursos naturais uma vez que a concorrência e o mercado externo, exigem padrões ambientais rigorosos para extração dos produtos minerais a serem comercializados(IBRAM, 2012), dessa forma, o comercio exterior funciona como um verdadeiro freio às práticas ambientais predatórias (REZENDE, 2016), para compensar a legislação brasileira, que em relação às atividades mineradoras no Brasil é extensa, e regida por uma série de regulamentações conflitantes, criando dificuldades na sua aplicação. Entre as regulamentações vigentes estão as resoluções do Conselho Nacional do Meio Ambiente (CONAMA) de nº.01 de 1986, que estabelece critérios básicos e diretrizes gerais para elaboração de Relatórios de Impacto Ambiental (RIMA); Resolução nº. 009 de 1990 que dispõe sobre normas específicas para a obtenção da licença ambiental para a extração de minerais, exceto as de emprego imediato na construção civil; Resolução $\mathrm{n}^{\mathrm{o}}$. 010 de 1990, que dispõe sobre o estabelecimento de critérios específicos para a extração de substâncias minerais de emprego imediato na construção civil e Resolução nº 02 de 1996, que dispõe sobre a compensação de danos ambientais causados por empreendimentos de relevante impacto ambiental.

Sendo assim, a aplicação das leis ambientais na área é fundamental para que a empresa tome providências em relação aos impactos causados e sua recuperação, necessário se faz, que a riqueza gerada pela indústria mineradora já instalada proporcione um efetivo desenvolvimento da comunidade e uma permanente integração com o meio ambiente, através de mecanismos que tornem a sociedade civil protagonista de sua relação com o território. 


\section{Agradecimentos}

Agradecemos a Coordenação de Aperfeiçoamento de Pessoal de Nível Superior (CAPES) pela concessão da bolsa de estudos ao primeiro autor, durante o mestrado.

\section{Referências Bibliográficas}

ALBUQUERQUE, U. P.; CRUZ DA CUNHA, L. V. F.; LUCENA, R. F. P.; ALVES, R. R. $\mathrm{N}$. Methods anda tecniques in ethnobiology and ethnoecology, Humana press, New York, 2014.

ALVES, J. J.; ARAÚJO, M. A.; NASCIMENTO, S. S. Degradação da caatinga: uma investigação ecogeográfica. Caminhos de Geografia, Uberlândia v. 9, n. 27, p. 143 - 155 2008.

ALVES, R.R.N.; GONÇALVES, M.B.R.; VIEIRA, W.L.S. Caça, uso e conservação de vertebrados no semiárido Brasileiro. Tropical Conservation Science, v. 5, n.3 p. 94-416, 2012.

BACCI, D. L. C.; LANDIM, P. M. B.; ESTON, S. M. Aspectos e impactos ambientais de pedreira em área urbana. Revista Escola de Minas,Ouro Preto, v. 59, n. 1, 2006.

BALZINO, M.; SECCATORE, J.; MARIN, T.; TOMI, G.; VEIGA, M. M. Gold losses and mercury recovery in artisanal gold mining on the Madeira River, Brazil. Journal of Cleaner Production, n. 102 p. 370-377, 2015.

BISQUERT, D. S. CASTEJON, J.M.P.; FERNANDEZ, G.G. The impact of atmospheric dust deposition and trace elements levels on the villages surrounding the former mining areas in a semi-arid environment (SE Spain). Atmospheric Environment, v. 152, p.256-269, 2017.

CABRAL, L. N.; PEREIRA, S. S; ALVES, T. L. B. Degradação ambiental e implicações para a saúde humana decorrentes da mineração: o caso dos trabalhadores de uma pedreira no município de Campina Grande/PB. Revista Hygeia, v. 8, n. 15, p. 104-118, 2012.

DANTAS, H. F. S. A.; SILVA, J. A. L.; MEDEIROS, M. C. S.; CABRAL, L. N. Análise da exploração minerária e seus impactos, visando a recuperação de áreas degradadas: estudo de caso no município de Pedra Lavrada-PB. Geo ambiente on line, n. 25, p. 42-56, 2015.

ENRÍQUEZ, M. A. R.; FERNANDES, F. R. C.; ALAMINO, R. C. J. A mineração das grandes minas e as dimensões da sustentabilidade. IN: FERNANDES, F. R. C.; ENRÍQUEZ, M. A. R; ALAMINO, R. C. J. (orgs). Recursos naturais e sustentabilidade natural. Grande Minas. v.1. Rio de Janeiro, 2011.

FALEIRO, F.F.; LOPES, L. M. Aspectos da mineração e impactos da exploração de quartzito em Pirenópolis-GO.Ateliê Geográfico, v. 4, n. 3, p.148-162, 2010.

FERNANDES, R. S; SOUZA, VALDIR, J. PELISSARI, V. B.; FERNANDES, S. T. Uso da percepção ambiental como instrumento de gestão em aplicações ligadas às áreas educacional, social e ambiental. Rede Brasileira de Centros de Educação Ambiental. Departamento de Ciências Florestais USP, Piracicaba, jul. 2004.

FERREIRA JÚNIOR, W. S.; SILVA, T. C.; ALBUQUERQUE, U. P. Biological and Evolutionary Bases of Human Perception of the Natural Environment. Introduction to Ethnobiology. 1ed.: Springer International Publishing, p. 105-110, 2016.

FREITAS, A. H. A.; MAGRIN, A. Multi criteria decision making to support sustainable water management in a mining complex in Brazil. Journal of Cleaner Production, n. 47, p. 118-128, 2013.

GIL, A. C. Como elaborar projetos de pesquisa.4. ed. - São Paulo: Atlas, 2002. 
GODFRID, J. El discurso pro-minero en Argentina. Un estudio de caso a partir de la empresa minera La Alumbrera. Revista Brasileira de Linguística Aplicada,v.16, n. 2, p. 257-276, 2016.

INSTITUTO BRASILEIRO DE MINERAÇÃO - IBRAM. Gestão para a sustentabilidade na mineração: 20 anos de história. 2012. Disponível em: http://www.ibram.org.br/sites/1300/1382/00002130.pdf. Acessado em: 21 de outubro de 2017.

JÁCOME, P. S.; PEREIRA, M. G.O. A extração mineral na cidade de Tenente Ananias $(\mathrm{RN})$, os impactos ambientais e o risco a saúde humana.Revista OKARA: Geografia em debate, v. 10, n. 3, p. 620-630, 2016.

KNABB, K. A.; EREL, Y.; TIROSH, O.; TAMMY, R.; LAPARIDOU, S.; NAJJAR, M.; LEVY, T. E. Environmental impacts of ancient copper mining and metallurgy: Multi-proxy investigation of human-landscape dynamics in the Faynan valley, southern Jorda. Journal of Archaeological Science, n. 74,p. 85-101, 2016.

LIMA, M. H. R.; TEIXEIRA, N. S. A contribuição da grande mineração às comunidades locais: uma perspectiva econômica social. Comunicação Técnica elaborada para o III Fórum de Mineração-Bens Minerais e Desenvolvimento Sustentável, realizado na Univ. Federal de Pernambuco-UFPE, n.25, v. 28, 2006.

LIPHADZI, S. M.; VERMAAK, A. P. Assessment of employees' perceptions of approaches to sustainable water management by coal and iron ore mining companies. Journal of Cleaner Production. n.153, p.608-625, 2017.

LYYTIMÄKI, J.; PELTONEN, L. Mining through controversies: Public perceptions and the legitimacy of a planned gold mine near a tourist destination. Land Use Policy, n. 54, p. 479486, 2016.

MATOS, R. Migração e urbanização no Brasil. Geografias, v. 08, n.1 07-23, 2012.

MCELIN, C. A.; BELLINI, M. Lixo e impactos ambientais perceptíveis no ecossistema urbano. Sociedade \& Natureza, v.20, n.1, p. 111-124, 2008.

NAVES, B. T. O.;FERNANDES, F. R. Mineração e saúde socioambiental: o desafio ético contemporâneo entre o risco e a sustentabilidade. Revista Direito Ambiental e sociedade, v. 5,n. 1, p. 106-128, 2015.

OLIVEIRA, J. A.; GONÇALVES, P. R.; BONVICINO, C.R.Mamíferos da Caatinga. In: LEAL, I. R.; TABARELLI, M.; SILVA, J. M. C. Ecologia e conservação da caatinga. Recife: Ed. Universitária da UFPE, p. 275- 335, 2003.

PATRÍCIO, M. C. M.; SILVA, V. M. A.; RIBEIRO, V. H. A. Conflitos socioambientais: estudo de caso em uma pedreira na Paraíba. Revista Polêmica, v. 12, n3, p. 528-544, 2013.

PONTES, J. C.; FARIAS, M. S. S.; LIMA, V. L. A. Mineração e seus reflexos socioambientais: estudo de impactos de vizinhança (EIV) causados pelo desmonte de rochas com uso de explosivos. Revista Polêmica, v. 12, n. 1, p. 77-90, 2013.

PRNO, J. An analysis of factors leading to the establishment of a social licence to operate in the mining industry. Resources Policy,v.38, p.577-590, 2013.

PONTES, J. C.; LIMA, V. L. A.; SILVA, V. P. Impactos ambientais do desmonte de rocha com uso de explosivos em pedreira de granito de Caicó-RN.Geociências, v. 35, n. 2, p.267276, 2016.

REZENDE, V. L. A mineração em minas gerais: uma análise de sua expansão e os impactos ambientais e sociais causados por décadas de exploração. Sociedade \& Natureza, v. 28, n. 3, p. 375-384, 2016.

RUFINO, A. C. S.; FARIAS, M. S. S.; DANTAS NETO, J. Avaliação qualitativa da degradação ambiental provocada pela mineração de areia-região do médio curso do Rio Paraiba. Engenharia Ambiental (Online), v. 5, p. 02, 2007. 
RUOSO, D.A percepção climática da população urbana de Santa Cruz do Sul/RS. Revista RA'EGA, n. 25, p. 64-91, 2012.

SANTOS, C. A.; NÓBREGA ALVES,R. R. Ethnoichthyology of the indigenous Trukápeople, Northeast Brazil. Journal of Ethnobiolgy and Ethnomedicine.v. 12, n. 1. doi:10.1186/s13002-015-0076-5. 2016.

SANTOS, C. A. B.; DE ALBUQUERQUE, U. P.; SOUTO, W. M. S.; ALVES, R. R. N. Assessing the Effects ofIndigenous Migration on Zootherapeutic Practices inthe Semiarid Region of Brazil. PLOS ONE,v. 11, n. 1:e0146657. doi:10.1371/journal.pone.0146657, 2016. SILVA, T. C.; CHAVES, L. S.; ALBUQUERQUE, U. P. What Is Environmental Perception?. Introduction to Ethnobiology. 1ed.: Springer International Publishing, p. 93-97, 2016.

UZN, F. V.; KELES, O. Th effects of nature education Project on the environmental awareness and behavior. Procedia Social and Behavioranl Sciences. 46, p. 2912-2916, 2012.

VACCAREZZA, L.S. Conflicto en torno a una intervención tecnológica: Percepción del riesgo ambiental, conocimiento y ambivalencia en la explotación minera de Bajo de la Alumbrera. Revista iberoamericana de ciência, tecnologia y sociedade,n.17, v. 6, p. 241260, 2011.

VIEIRA, E. A. A (in) sustentabilidade da indústria da mineração no Brasil. Estação Científica (UNIFAP), v. 1, n. 2, p. 01-15, 2011.

VILLAR, M. L.; ALMEIDA, A. J.; LIMA, M. C. A; ALMEIDA, J. L. V.; SOUZA, L. F. B.; PAULA, V. S. A percepção ambiental entre os habitantes da região noroeste do estado do Rio de Janeiro. Escola Anna Nery. Revista de Enfermagem, v. 12, p. 285-290, 2008.

XIAO, R.; WANG, S.; L. I. R.; J. WANG, J.; ZHANG, Z. Soil heavy metal contamination and health risks associated with artisanal gold mining in Tongguan, Shaanxi, China. Ecotoxicology and Environmental Safety, v. 141, p.17-24, 2017.

YAN-XIA, L.; LEI1, Y.; YA-JUN1, C.; SAUD, S.; JING-JING, L.; HUI, Y.; LI-YUAN, Z. Landscape Transformation in Mining Wastelands.Journal of Northeast Agricultural University, v. 23 n. 1, p.83-88, 2016.

ZELEŇÁKOVÁ, M.; ZVIJÁKOVÁ, L. Risk analysis within environmental impact assessment of proposed construction activity. Environmental Impact Assessment Review, n. 62, p.76-89, 2017. 